\title{
Application of Fuzzy Logic in Modeling Market Brand Value
}

\author{
Nenad Stojanovic \\ Faculty of Agriculture, University of Banja Luka, Banja Luka, Bosnia and Herzegovina \\ Email address: \\ nenad.stojanovic@agro.unibl.org
}

\section{To cite this article:}

Nenad Stojanovic. Application of Fuzzy Logic in Modeling Market Brand Value. American Journal of Mathematical and Computer Modelling. Vol. 4, No. 1, 2019, pp. 1-15. doi: 10.11648/j.ajmcm.20190401.11

Received: December 10, 2018; Accepted: February 7, 2019; Published: February 28, 2019

\begin{abstract}
Dominant group of factors that influence the brand market value, according to Aaker are: customer loyalty to the brand, perceived brand quality, brand familiarity and brand associations in comparison to competitors. Functional dependence between these factors and market brand value is not expressed in exact way, although these factors are quantitatively expressed with suitable index [17]. Modern technique of fuzzy logic and fuzzy sets implementation for problem solving in areas of finance and management is based on FLC (fuzzy logic control) process. Implementation of FLC process In this paper is represented in order to determine brand market value that is mathematical model is constructed using fuzzy numbers and fuzzy logic, which is used to quantitatively determine brand market value. Brand market value $\mathrm{TV}=\mathrm{f}(\mathrm{L}, \mathrm{P}, \mathrm{K}, \mathrm{A})$ is expressed depending on customer loyalty $(\mathrm{L})$ towards the brand, perceived brand quality $(\mathrm{K})$, brand familiarity $(\mathrm{P})$ and brand association (A) received from the customers, where the measurement rates are evaluated using by fuzzy numbers.
\end{abstract}

Keywords: FLC Process, Fuzzy Logic, Mathematic Modeling, Market Brand Value

\section{Introduction}

Meaning of the certain term is determined bu using attributes. For example, loyalty of the customer can be low or high. It's obvious that we connot set to determine certain value when loyalty stops being low or high. The line between these two attributes is elastic, and it mostly depends from personal evaluation and circumstances of the term, that is evaluated [1]. If we want precise specification of this term then we can say that loyalty is either very low, low, medium, high or very high. Obviously, larger number of attributes contributes to linguistic specification of the term, but the border line problem still remains open. Fuzzy sets could play role of elastic borders between certain attributes.

We join fuzzy set to each attribute individually and determine domain which has clear semantic meaning. Generally speaking, we can say that family of fuzzy sets $A=\left\{A_{1}, A_{2}, A_{3}, \ldots, A_{n}\right\}$ represents framework for cognition of certain term $X$ if every element of the term $\mathrm{X}$ is joined with at least one fuzzy set with none-zero degree of dependence. In fuzzy set theory characteristic function $\chi A(x)$, of membership of the elements $x$, to the set $A$

$$
\chi A(x)= \begin{cases}1 & x \in A \\ 0 & x \notin A\end{cases}
$$

is generalized by membership function $\mu_{A}$. Degree of element membership $x$ to the fuzzy set is given by real value from interval $[0,1]$ that is $\mu_{A}(x): A \rightarrow[0,1]$. Fuzzy set $A$ is completely determined by set of organized pairs:

$$
A=\left\{\left(x, \mu_{A}(x)\right) \mid x \in U, \mu_{A}(x) \in[0,1]\right\}
$$

Where $\mu_{A}(x)$ is degree of element $x$ membership to the set $A$ while $U$ represents universal set. If $\mu_{A}(x)$ is higher, then there is more truth in statement that element $x$ belongs to set $A$. Fuzzy sets expressed in triangular form are the most practical and most often used form of membership function figure (Figure 1). We express triangular fuzzy set in shorter way $A=[l, m, n]$ and membership function $\mu_{A}(x): U \rightarrow[0,1]$ is expressed by folloving equations

$$
\mu_{A}(x)=\left\{\begin{array}{cc}
0 & n<x<l \\
\frac{x-l}{m-l} & l \leq x \leq m \\
\frac{n-x}{n-m} & m \leq x \leq n
\end{array}\right.
$$

Other methods are also used besides triangular fuzzy number: L function, $\Gamma$ function, trapezoidal shape or $\Pi$ function and others [2]. Variable value $x$ for which $\mu_{A}(x)=1$ is valid, is called center of the fuzzy set $A$. If many of these variables exist, such is the case in trapezoidal fuzzy set $A=\left[a_{1}, a_{2}, a_{3}, a_{4}\right]$ (Figure 1), then the set of all values $x$ for 
which is $\mu_{A}(x)=1$ we call nucleus of fuzzy set $A$ and is expressed by $\operatorname{Ker}(A)=\left\{x \mid x \in U \wedge \mu_{A}(x)=1\right\}$. Carrier of fuzzy set $A$ is set of all values $x$ for which is $\mu_{A}(x)>0$ and is expressed with $\sup p(A)=\left\{x \mid x \in U \wedge \mu_{A}(x)>0\right\}$

Is particularly significant for fuzzy logic practical implementation in order to manage systems existence of fuzzy set with one element for which membership function has value of 1 [3], [4]. For given fuzzy set $A$ and $\alpha \in[0,1]$ set $A_{\alpha}=$ $\left\{x \in X \mid \mu_{A}(x) \leq \alpha\right.$ is called $\alpha$ cross-section of fuzzy set $A$ (Figure 1). Membership function $\mu_{A}(x)$ of fuzzy set $A$, by application of $\alpha$ cross-section. can dismember an infinite num
$\chi_{\mathrm{A}_{\alpha}(\mathrm{x})}$ is characteristic function of set $\mathrm{A}_{\alpha}$.

Definition 1.1. [5] Number is considered to be a fuzzy number for fuzzy set $A$ in the set of real numbers if following is satisfied:

1. A is convex set,

2. There is exactly one $\overline{\mathrm{x}} \in \mathrm{R}$ so therefore $\mu_{A}(x)=1$,

$$
\operatorname{Ker}(\mathrm{A})=\overline{\mathrm{x}} \text {. }
$$

3. Membership function $\mu_{\mathrm{A}}(\mathrm{x})$ for $\bar{x} \in R$ is at least by its parts uninterrupted.

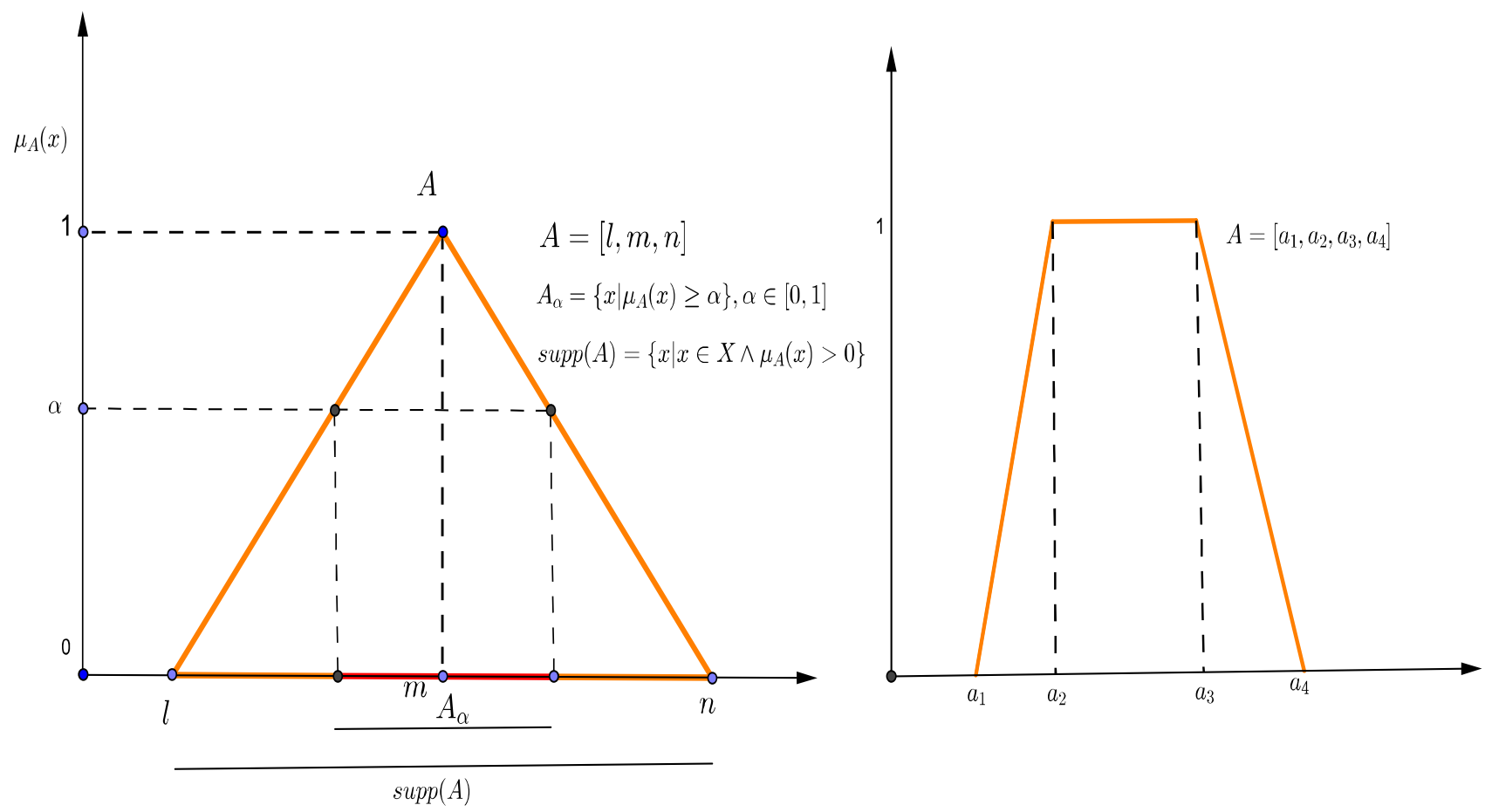

Figure 1. Fuzzy numbers triangular and trapezoidal.

We represent evaluation parameters of brand market value with fuzzy numbers, triangular, trapezoidal and $\Gamma$-gama (Figure 1), because they contain uncertainty resulted by measurement error and clearly unidentified borders between qualitative states. Thus, Zadeh's expended principle is important [5].

Definition 1.2. [4] Let's $A_{1}, A_{2}, \ldots, A_{n}$ are fuzzy subsets of classical sets $\mathrm{X}_{1}, \mathrm{X}_{2}, \ldots, \mathrm{X}_{\mathrm{n}}$ respectively, and mapping is given $f: X_{1} \times X_{2} \times \ldots \times X_{n} \rightarrow Y$ such that for each $n$, $\left(x_{1}, x_{2}, \ldots, x_{n}\right) \in X_{1} \times X_{2} \ldots \times X_{n}$ is valid $f\left(x_{1}, x_{2}, \ldots, x_{3}\right)=$ $y \in Y$.

Then $B=f\left(A_{1}, A_{2}, \ldots A_{n}\right)$ is a fuzzy subset from $Y$ and its membership function is

$$
\mu_{\mathrm{B}}=\left\{\begin{array}{cc}
\sup _{\mathrm{y}} \min \left\{\mu_{\mathrm{A}_{1}}\left(\mathrm{x}_{1}\right), \ldots, \mu_{\mathrm{A}_{\mathrm{n}}}\left(\mathrm{x}_{\mathrm{n}}\right)\right\} & \text { if exist } y=f\left(x_{1}, x_{2}, \ldots x_{n}\right) \\
0 & \text { otherwise }
\end{array}\right.
$$

If $A$ and $B$ are fuzzy subsets of universal sets $U_{1}, U_{2}$, then Descarte's product $A \times B$ is fuzzy relation $\mathrm{R}$ in the $\mathrm{U}_{1} \times \mathrm{U}_{2}$ and we use label $R=A \times B$ and further is valid for function $\mu_{A}: U_{1} \times U_{2} \rightarrow[0,1]$

$$
\mu_{R}(x)=\min \left[\mu_{A}(x), \mu_{B}(x)\right] .
$$

Generally, if $A_{1}, A_{2}, \ldots, A_{n}$ are fuzzy subsets of universal sets $\mathrm{U}_{1}, \mathrm{U}_{2}, \ldots, \mathrm{U}_{\mathrm{n}}$ then Descarte's product $\mathrm{A}_{1} \times \mathrm{A}_{2} \times \ldots \times \mathrm{A}_{\mathrm{n}}$ is fuzzy relation in the set $U \times U \times \ldots \times U_{n}$. It is labeled as $R=A_{1} \times$ $A_{2} \times \ldots \times A_{n}$ and further is valid

$$
\begin{gathered}
\mu_{R}\left(x_{1}, x_{2}, \ldots, x_{n}\right)=\min \left\{\mu_{A_{i}}\left(x_{i}\right) \mid x_{i} \in U_{i}\right. \\
i=1,2, \ldots, n\} .
\end{gathered}
$$

Theory based on fuzzy sets enables reasoning with undefined information. Original idea of making decisions based on unprecise data combining linguistic rules comes from Zade who those calls reasoning approximate or fuzzy reasoning. [6]

Fuzzy reasoning represents conclusion procedure based on premises which contains linguistic expressions. Central characteristic of this theory is representation of propositions as commands that join fuzzy sets. Input and output variables in the system phase are linguistic variables. Linguistic variables 
are expressed in form $(\mathrm{x}, \mathcal{F}, \mathrm{U}, \mathrm{M})$ where: $\mathrm{x}$-variable name $\mathcal{F}$ space of linguistic values which variables $\mathrm{x}$ can absorb, that is space of fuzzy sets over area $U$.

$U$ - quantitative area of consideration of variable $\mathrm{x}$ under which it absorbs linguistics value, M-semantic function (rule) of space connection $\mathcal{F}$ with area $U$, i.e. $M \cdot U \rightarrow F$. [3]

Matching degree of membership is joined to all possible values of input and output variables [7]. One of the most important characteristics of fuzzy logic is possibility to express degree of uncertainty in human thinking and his/her subjectivity. Fuzzy logic therefore covers subjectivity of human reasoning, emotions and language.

Structure $P: \mathrm{x}$ is A where $x \in U$ is linguistic variable, $A \in \mathcal{F}$ space of linguistic values which variable $x$ can, that it, space of fuzzy sets defined over area. $U$ is called proposition. If two fuzzy propositions in interrelationship, then fuzzy relation is created. Fuzzy relation of two proportions has the following form, $R: x$ is $A$ and $y$ is $B$, where $x \in U_{1}, y \in U_{2}$ is linguistic variable, $A \in \mathcal{A}, B \in \mathcal{B}$ are fuzzy sets. In fuzzy relations the following function appears $\mu_{R}(x, y):[0,1] \times[0,1] \rightarrow$ $[0,1]$ which represents truthfulness of relation $\mathrm{R}$.

$$
\begin{gathered}
R=\left\{\left(\mu_{R}(x, y), x, y\right) \mid x \in U_{1}, y \in U_{2}\right\}, \\
\mu_{R}(x, y)=\rho\left\{\mu_{A}(x), \mu_{B}(y)\right\}
\end{gathered}
$$

where $\rho\{$.$\} represents one of the operators, and by choosing$ that one it creates function $\mu_{R}(x, y)$ and indirectly has effect on fuzzy controller structure. In our case $" \wedge$ " appears as operator $\rho\{$.$\} [8]. Fuzzy rule base represents medium part of fuzzy$ controller. Fuzzy rule as primary part of base has form: If $R$ then $P^{\prime \prime}$ where $R$ and $P$ represent fuzzy relation, that is proposition. Is important to give meaning for fuzzy rule in the form of trutheuuness of proposition $P$, after membership function $\mu_{R}($.$) of relation R$ is determined. Usually, fuzzy implications of type $\min$ and product are used in fuzzy controller which gives meaning $\mu_{R \rightarrow P}=\min \left(\mu_{R}, \mu_{P}\right)$ to the rule "If $\mathrm{R}$ then $\mathrm{P}$ ", $\mu_{R \rightarrow P}=\mu_{R} * \mu_{P}$, where $R \rightarrow P$ represents rule. Min operation of fuzzy implication is called Mamdani implication and it is one of the mostly used implication in fuzzy controller [9].

\section{Indicator of Brand Evaluation}

Brand is name, term, symbol or design or combination of all of those elements. It is focused to recognize products or a service of one or group of producers on the market. It also represents tool for product differentiation from competitors who produce the same or similar products on the market [10].

Brand of product/service is used for communication between business subjects and customers, by offering their products/services companies try to make themselves more recognizable in business environment [11].

Customers have more active relationship towards brand because it helps during the purchase decision making. For companies brand is a source of competitive advantage and creation of financial income, where as for customers it's sign of quality, decrease of purchase risk and symbolic tool for making decisions [12].
Brand value is impacted by its overall identity, as well as characteristic that customers recognize. There are two conceptual brand values: market value and financial value, while at the same time scholars suggest that it's hard to make difference between them because they are mutually connected and inter wined linked. Quantitative determination of brand market value is subject of interest for many experts from different economic backgrounds [13].

Brand Market Value is based on customers behavior and atitudes, while financial value is based on financial parameters [14]. Brand market value represents relationship between customer and brand. Dominant group of factors that influence the brand market value, acording to Aaker is model are: customer loyalty to the brand, perceived brand quality, brand familiarity and brand associations in comparison to competitors [15]. Each of mentioned brand market value indicators is evaluated by quantitatively suitable index.

Brand loyalty. One of the most basic indicators of brand market value is loyalty from existing and potential customers, which is measured by their willingness for repetitive purchase of products/service. Customer loyalty towards brand is expressed by the fact that brand is able to fulfill their emotional and functional needs, with reasonable and satisfying price. Depending on their feelings developed for the certain brand they create loyalty. [14] Brand loyalty is also expressed by rate of customer retention $s_{z}$, [16] which represents total number of customers who use brand, $n_{k}$ and total number of customers in sample $n_{u}$ (or on specific area) therefore further formula is valid $s_{z}=\frac{n_{k}}{n_{u}}$

Perceived quality. Perceived brand quality is tightly connected with product quality that brand offers and promises. Many companies claim that quality is one of the main indicators for creation of position on the market. Depending on how customers perceive quality, sales increases or decreases. It's measured by complaints rate, label $s_{r}$, based on the product/service quality which represents relationship between number of customers who made complaints $n_{r}$ and total number of customers in sample, $n_{u}$ therefore further formula is used $s_{r}=\frac{n_{r}}{n_{u}}$. From this is derived that larger number of reclamations indicates lower level of quality and vice versa.

Brand familiarity. Brand familiarity and its existence in customer's environment depend on how quickly customers recognize brand on the market and how familiar they are with its values. Based on that there are two types of familiarities: spontaneous familiarity- when customer is able to remember the brand without previous thinking and remembering, that is how brand is dominant in customer's mind and familiarity with reminder-when customer, is able to remember the brand after receiving certain information. Brand familiarity is measured quantitatively with familiarity rate $s_{p}$ which represents relationship between number of customers who are familiar with brand $n_{p}$, and total number of customers in sample $n_{u}$ therefore further formula is used $s_{p}=\frac{n_{p}}{n_{u}}$, [16].

Brand association. Basic function of the brand value is to create association with the name. Associations that we connect to the certain brand are factors of their differentiation. Based 
on developed association towards brand relationship with customer is created. Customer can link brand with positive, negative or both experiences. [14] Brand association is created by customer's perception while using products/services. It's connected to expectation realization of products/services. We can group it into two:

1. Experience is positive - customer receives more than expected while consuming brand, and therefore increases brand perceived value.

2. Experience is negative - customer receives less than expected while consuming brand, and therefore decreases brand perceived value.

Brand association we can be quantified by rate of positively preferred experiences $s_{p p}$, and by rate of negatively preferred experiences $n_{p p}$. Rate of positively preferred experiences represents relationship between number of positive experiences and total number of preferred experiences (positive and negative) whitch resulted from brand consumption.

If $n_{p}$ is total number of positively preferred experiences, $n_{q}$ is total number of negatively preferred experiences, than rate of positively preferred experiences $s_{p p}$ is given by relation $s_{p p}=\frac{n_{p}}{n_{p}+n_{q}}$, and rate of negatively preferred experiences $s_{n p}=1-s_{p p}=\frac{n_{q}}{n_{p}+n_{q}}$.

Further is valid $s_{p p}+s_{n p}=1$. In dependence of rate value of positively $s_{p p}$, and negatively $s_{n p}$ preferred experiences, we can distinguish further brand associations:

mainly positive- if rate of positive experience is larger than rate of negative experiences $s_{p p}>s_{n p}$,

mainly negative-if rate of positive experience is smaller than rate of negative experiences i.e $s_{p p}<s_{n p}$.

if rate of positive experienc is equal undecided-to rate of negative experience $s_{p p}=s_{n p}$.

Each of the measured indicators: loyalty, perceived quality, familiarity and brand associations has impact on brand market value, [18]. If $T V$ is used to label brand market value, than we express functional dependence of $T V$ from those indicators in the following way $T V=f(L, K, P, A)$ where

$L$ represents value of customer loyalty towards brand,

$K$ represents value of perceived quality,

$P$ represents evaluated brand familiarity,

$A$ represents evaluated brand associations.

It is very hard process to exactly determine brand market value as there are many parameters of human behavior and thinking which influence the evaluation, which is especially hard to quantify. Therefore in expressed functional relationship $T V=f(L, K, P, A)$ even though quantitative indicator values $L, K, P, A$ are exactly determined, still making conclusion about brand market value based on those values is unreliable because of evaluation of parameters, sample size on which parameters are evaluated, as well as nonexistence of functional relationship between those parameters. Therefore it is justified to use approximate (fuzzy) reasoning in measurement of brand market value and all conclusion made based on those measurements.

\section{Construction of Fuzzy Numbers and Confidence Interval of Basic Set Proportion}

Let it be that variable $x$ is given $(x, \mathcal{A}, U, M)$ classified in definition area $U=[0, a], a \in \mathbb{R}$ of $p$ family fuzzy numbers

$$
\mathcal{A}(x)=\left\{\left(\mathrm{x}, \mu_{A_{i}(x)}\right) \mid x \in A_{i}, A_{i} \subset \mathcal{U}_{i}, i=1,2, \ldots, p\right\}
$$

with membership function $\mu_{A_{i}(x)}$. We label with $B_{i}, i=$ $1,2, \ldots, p-1$ intersection points $\mu_{A_{i}(x)} \cap \mu_{A_{i+1}(x)}$ with $a_{1}, a_{2}, \ldots, a_{i-1}, a_{i}, a_{i+1}, \ldots, a_{p-1}$ their projection on $O x$ axis. Points $a_{i}$ divide segments $\mathcal{U}=[0, a]$ into disjoint subintervals.

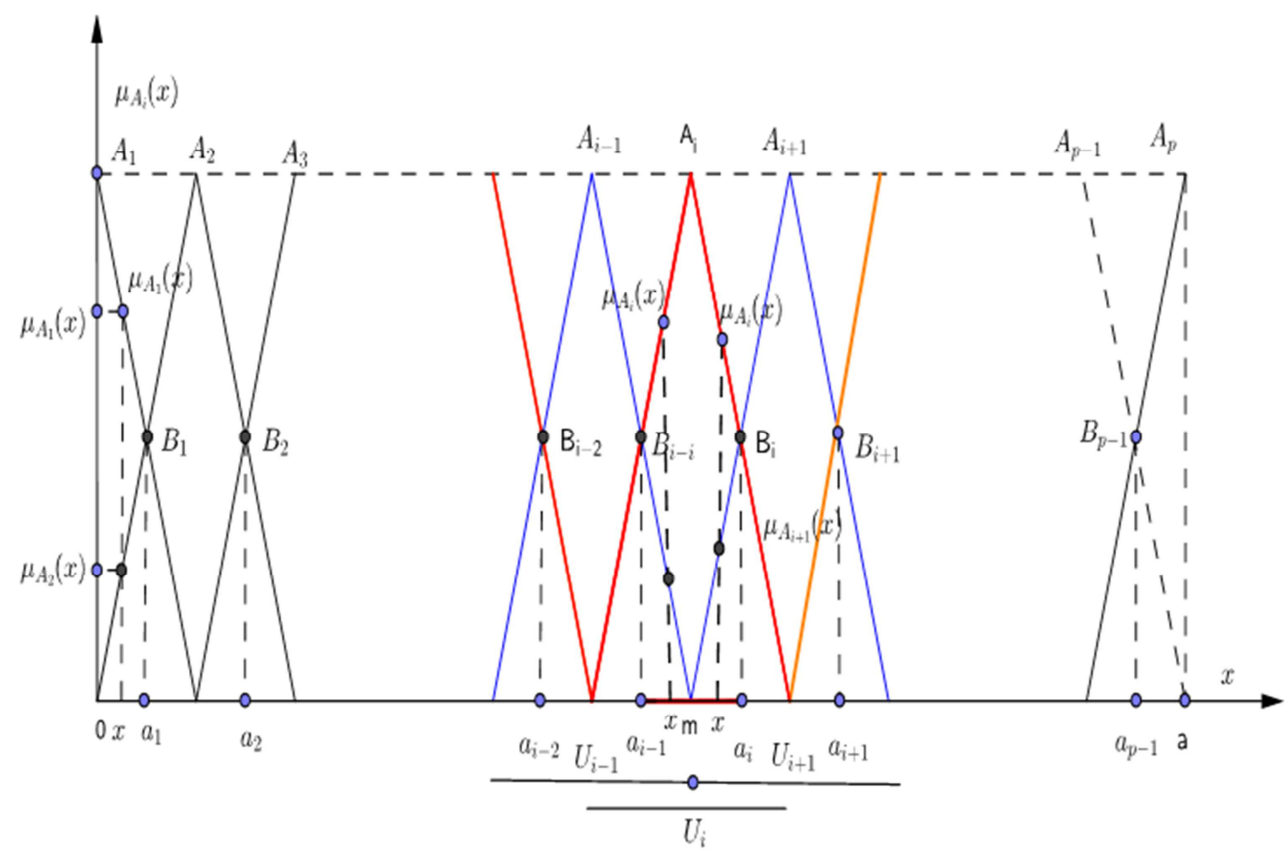

Figure 2. Family fuzzy numbers $\mathcal{A}(x)$ and interval of dominant membership. 
Let it be that fuzzy number $A_{i} \subset \mathcal{A}(x)$ is defined on area $u_{i} \subset \mathcal{U}$.

Definition 3.1. Interval $\left[a_{i-1}, a_{i}\right]=\left\{x \mid a_{i-1} \leq x \leq a_{i}, x \in\right.$ $\left.A_{i}\right\} \subset \mathcal{U}_{i}$ is called interval of dominant membership of variable $x$ towards fuzzy number $A_{i}$ in relation to fuzzy number $A_{1}, ., A_{i-1}, A_{i}, A_{i+1}, \ldots, A_{p} \in \mathcal{A}(x)$ defined or partially in area $\mathcal{U}_{i}$, if further is valid for all variable values $x \in$ $\left[a_{i-1}, a_{i}\right]$

$$
\mu_{A_{i}(x)} \max _{x \in\left[a_{i-1}, a_{i}\right]}\left\{\mu_{A_{1}(x)}, \mu_{A_{2}(x), \ldots,} \mu_{A_{p}(x)}\right\}
$$

Points $x=a_{i}, i=1,2, \ldots . p-1$ points of change dominant membership on area $\mathcal{U}_{i}$ of fuzzy number $A_{i-1}, A_{i}, A_{i+1}$.

If $\left[a_{i-1}, a_{i}\right] \subset \mathcal{U}_{i}$ is dominate membership interval (Dominant affiliation) of variable $x$ towards fuzzy number $A_{i}$ defined in the area $\mathcal{U}_{i}$ we write (Figure 2)

$$
\operatorname{Daf}_{A_{i}}(x)=\left[a_{i-1}, a_{i}\right]=\left\{x \mid a_{i-1} \leq x \leq a_{i}, x \in A_{i}\right\}
$$

Definition 3.2. If fuzzy set $A \in \mathcal{A}(x)$ is defined over $\mathcal{U}$ of universal set then the difference $\mathcal{U} \backslash \operatorname{Daf}(A)=\overline{\operatorname{Daf}(A)}$ is called complement of dominant set $\operatorname{Daf}(A)$ and we define it with

$$
\overline{\operatorname{Daf}(A)}=\{\mathrm{x} \mid \mathrm{x} \in A \wedge x \notin \operatorname{Daf}(A)\}
$$

Each FLC (fuzzy logic control) process has input and output values which are given in form of linguistic variables and are mostly based on if-then rules. Now us determine relationship between fuzzy numbers and rates $s_{z}, s_{r}, s_{p}, s_{p p}$ which are used to evaluate parameter values $L, K, P, A$ measured in the sample.
Quantitative indicator value of brand market value is measured by appropriate rate-proportion based on sample $p=s=\frac{m}{n}$ where $m$ is a number of customers with required characteristic and $n$ is a number of respondents in a sample. For large samples, $n \geq 50$, distribution of sample proportion is closely equal to normal distribution and we can take $p$ as approximation of basic set (population) proportion (rate) $\pi$ [19].

Confidence interval of basic set proportion $\pi$ based on sample data, with given confidence coefficient $1-\alpha$ is expressed with

$$
p-z_{\frac{\alpha}{2}} \sqrt{\frac{p(1-p)}{n-1}} \leq \pi \leq \mathrm{p}+z_{\frac{\alpha}{2}} \sqrt{\frac{p(1-p)}{n-1}}
$$

Let $d=z \frac{\alpha}{2} \sqrt{\frac{p(1-p)}{n-1}}$ be an interval of proportion evaluation $\pi$, which can also be written in a shorter form $\pi \in$ $[p-d, p+d]$. It is noticeable that fallowing is valid for proportion value evaluation $\pi \in\left[a_{1}, a_{2}\right]$ of basic set and any proportion value $\pi^{\prime} \in\left[0, a_{1}\right), \pi^{\prime \prime} \in\left(a_{2,1}\right]$ is $\pi^{\prime}<\pi<\pi^{\prime \prime}$.

Let it be that element characteristic of a basic set, that is observed, is evaluated with attributes: very lower than average, lower than average, average, higher than average, very higher than average. Then we form fuzzy numbers, determined by those attributes, as it follows.

Family of fuzzy numbers is markeo $\mathcal{F}(s)$ with described characteristics over the area $\mathcal{U}=[0,1]$

\section{$\mathcal{F}(s)=\{$ very lower than average, lower than average, average, higher than average, very higher than average $\}$}

and let membership of appropriate fuzzy number be given by triangular and trapezoidal membership function.

Quantitative consideration area of observed variable under which it asquires linguistic value is an interval $[0,1]$. We take into consideration that dominant membership interval $[\mathrm{p}-$ $\mathrm{d}, \mathrm{p}+\mathrm{d}]$ of fuzzy number $\mathrm{P} \equiv$ average value represents asymmetric interval in relation to medium value $p=0.5$ of interval $[0,1]$ (Figure 3).

Let's determine dominant membership interval and value are by observed fuzzy numbers if $p=0.5$ and $\alpha=0.05$. If we put into equation $d= \pm Z_{\frac{\alpha}{2}} \sqrt{\frac{p(1-p)}{n-1}}$ values $p=0.5, Z_{\frac{\alpha}{2}}= \pm 1.96$ we get $d= \pm \frac{0.98}{\sqrt{n-1}} \pm \frac{1}{\sqrt{n-1}}$, which together with limitations for large samples $n \leq 30$ gives result for $d \leq 0.1859$.

Using obtained results we find the following;

-fuzzy number $M M P[0,0,0.2,0.2]$ dominant membership interval $(M M P)=[0,0.2]=U_{M M P}$,

-fuzzy number $M P[0,0,0.2,0.5]$ has dominant membership interval $\operatorname{Daf}(M P)=[0.2,0.3141] \approx[0.2,0.3]$ and its value area is $U_{M P=}[0,0.5]$

-fuzzy number $P[0.2,0.5,0.8]$ is $\operatorname{Daf}(P)=[0.5-$ $0.1859,0.5+0.1859]=[0.3141,0.6859] \approx[0.3,0.7]$, value area is $U_{P=}[0.2,0.8]$ -fuzzy number $V P[0.5,1,1]]$ is $\operatorname{Daf}(V P)=[0.6859,1] \approx$ $[0.7,1]$ and its value area is $U_{V P=}[0.5,1]$

-fuzzy number $M M P=[0.8,0.8,1,1]]$ has dominant membership interval $\operatorname{Daf}(M M P)=[0.8,1]$.

From the above mentioned and according to the fuzzy set definition further is valid:

-Fuzzy number "very lower than average" $=M M P=[0,0$, $0.2,0.2]$ is completely determined by arranged pairs set

$$
M M P(s)=\left\{\left(s, \mu_{M M P}\right) \mid s \in \mathcal{U}=[0,0.2], \mu_{M M P}(s) \in[0,1]\right\}
$$

Where $\mu_{M M P}(s)$ is a membership degree of elements to the set $M M P s$ of given membership function

$$
\mu_{M M P}(s)=\left\{\begin{array}{cc}
1 & 0 \leq s \leq 0.2 \\
0 & s \geq 2
\end{array}\right.
$$

-Fuzzy number "lower than average" $\equiv M P=[0,0,0.2,0.5]$ is completely determined by arranged pairs set

$$
M P(s)=\left\{\left(s, \mu_{M P}\right) \mid s \in \mathcal{U}=[0,0.5], \mu_{M P}(s) \in[0,1]\right\}
$$

with following membership function of fuzzy number

$$
\mu_{M P}(s)=\left\{\begin{array}{cc}
1-\mu_{P}(s) & 0 \leq s \leq 0.5 \\
0 & s \geq 0.5
\end{array}\right.
$$


-Fuzzy number "average" $\equiv P=[0.2,0.5,0.8]$ is completely determined by arranged pairs set

$$
P(s)=\left\{\left(s, \mu_{P}\right) \mid s \in \mathcal{U}=[0.2,0.8], \mu_{P}(s) \in[0,1]\right\}
$$

with following membership function of fuzzy number

$$
\mu_{P}(s)=\left\{\begin{array}{cc}
0 & 0.8 \leq s \leq 0.2 \\
\frac{10 s-2}{3} & 0.2 \leq s \leq 0.5 \\
\frac{8-10 s}{3} & 0.5 \leq s \leq 0.8
\end{array}\right.
$$

-Fuzzy number "larger than average" $\equiv V P=[0.5,0.8,1,1]$ is completely determined by arranged pairs set

$$
V P(s)=\left\{\left(s, \mu_{V P}\right) \mid s \in \mathcal{U}=[0.5,1], \mu_{V P}(s) \in[0,1]\right\}
$$

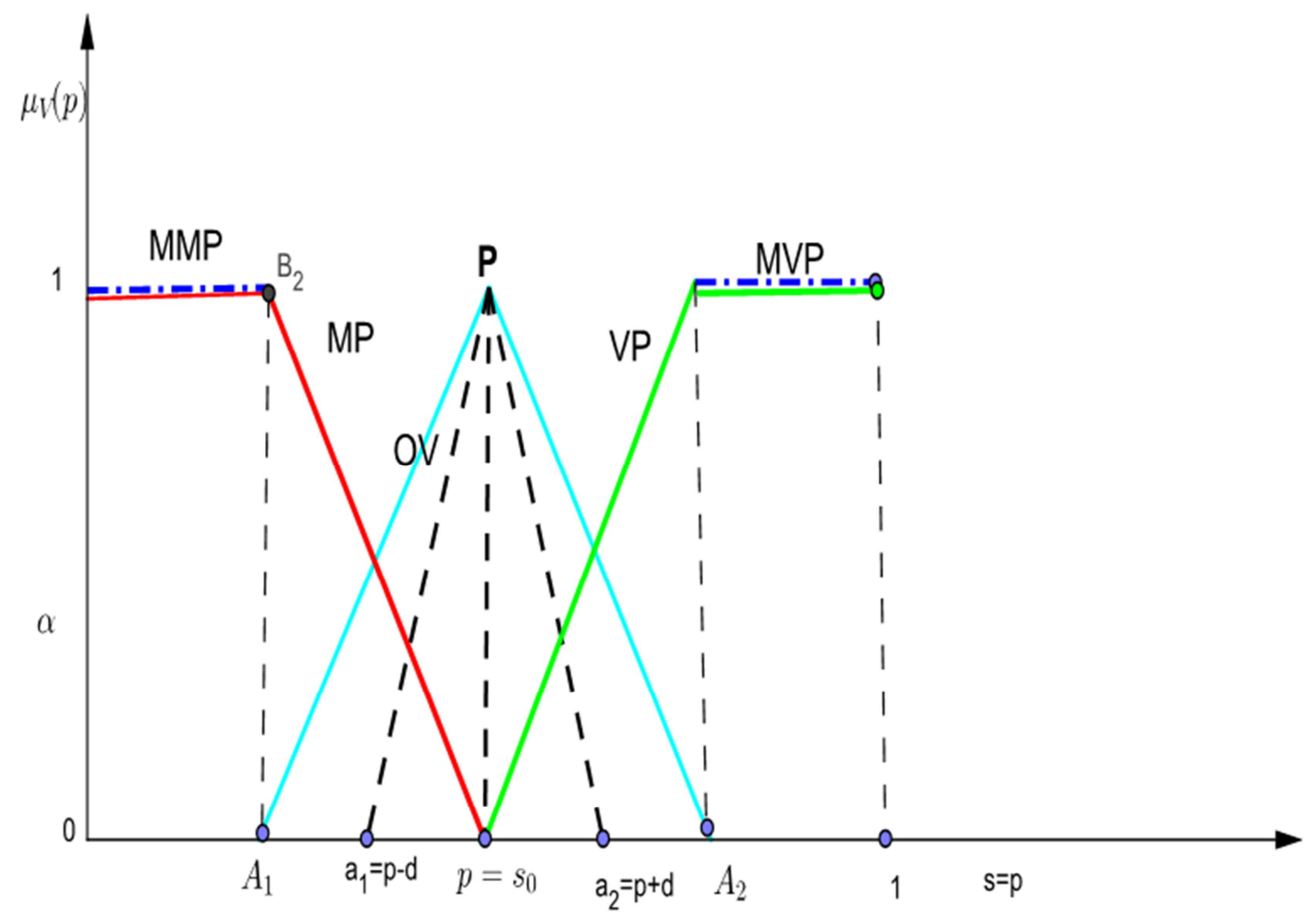

Figure 3. Membership function family, $\mathcal{F}(s)=\{\{M M P, M P, P, V P, M V P\}$ fuzzy number.

Similarly, when a perceived characteristic is evaluated with three fuzzy attributes then we define three fuzzy numbers over interval $[0,1]$ (then $M M P=M V P=0$ ) with appropriate membership function. Graphical representation of fuzzy numbers family $\mathcal{F}(s)$ is in Figure 3.

Let it be that "perceived value" $\equiv O V$ fuzzy number is obtained by calculating appropriate rate $s$, defined on interval $\mathcal{U}_{O V}=[s-d, s+d] . \quad$ As $\quad \operatorname{Daf}(O V) \subseteq \operatorname{Daf}(P) \approx$ $[0.3,0.7]$ and $\mathcal{U}_{O V}=[s-d, s+d] \subseteq[0.2,0.8]=\mathcal{U}_{P}$ fuzzy set $O V=$ "perceived value" can be evaluated as "average," which gives us implementation confirmation of justification of fuzzy numbers usage for evaluation of market brand value parameters based on confidence interval of basic set with following membership function of fuzzy number

$$
\mu_{V P}(s)=\left\{\begin{array}{cc}
1-\mu_{P}(s) & 0.5 \leq s \leq 1 \\
0 & s \leq 0.5
\end{array}\right.
$$

-Fuzzy number "very larger than average" $\equiv M V P=$ $[0.8,0.8,1,1]$ is completely determined by arranged pairs set

$$
\operatorname{MVP}(s)=\left\{\left(s, \mu_{M V P}\right) \mid s \operatorname{MVP}, M V P \in \mathcal{U}=[0.8,1],\right.
$$

$\left.\mu_{M V P}(s) \in[0,1]\right\}$ with following membership function of fuzzy number

$$
\mu_{M V P}(s)=\left\{\begin{array}{cc}
1 & 0.8 \leq s \leq 1 \\
0 & s<0.8
\end{array}\right.
$$

proportion.

\section{Modeling of Input Variables of Model}

Using above mentioned procedure of fuzzy numbers construction, we will construct fuzzy numbers of input variables in model. We introduce labels and scales for linguistic input variables as follows:

1. We label linguistic variable customer loyalty, with $x$ and write in form $\left(x, \mathcal{L}(x), \mathcal{U}_{1}, M_{1}\right)$. Value area which variable $\mathrm{x}$ can absorb we define, according to the stated construction fuzzy set family, as

$$
\begin{gathered}
\mathcal{L}(x)=\{\text { completely loyal, partly loyal, satisfied, satisfied by habit, disloyal }\} \\
=\{P L, D L, Z, Z N, N L\}=\left\{L_{1}, L_{2}, L_{3}, L_{4}, L_{5}\right\}=\left\{\left(x, \mu_{L_{i}}(x)\right) \mid x \in L_{i}, L_{i} \subseteq \mathcal{U}_{1}\right\}, i=\overline{1,5} .
\end{gathered}
$$


Quantitative area $\mathcal{U}_{1}$ which belongs to the domain of those fuzzy sets belong to is value interval $\mathcal{U}_{1}=[0,1]$ of customer retention rate, and semantic function $M_{1}: \mathcal{U}_{1} \rightarrow \mathcal{L}(x)$ is triangular, trapezoidal or $\Gamma$ membership function, in market $\mu_{L_{i}}(x)$. Fuzzy numbers of family $\mathcal{L}(x)$ have further meaning, membership function in relation to domain value and described constructive approach, and graphical representation of fuzzy numbers is given in Figure 3.

L1. Fuzzy number

$P L=\left\{\left(x, \mu_{P L}(x)\right) \mid x \in \mathcal{U}_{P L}=[0.8,1]\right\} \quad$ means that customers are completely loyal to the brand. In this case value of customer retention rate $s_{Z}$ belongs to interval $0.8 \leq s_{Z} \leq$ 1. Expression of fuzzy number in trapezoidal form is $P L=$ $[0.8,0.8,1,1]$.

Membership function of fuzzy number is

$$
\mu_{P L}(x)=\left\{\begin{array}{cc}
1, & 0.8 \leq x \leq 1 \\
0, & x<0.8
\end{array}\right.
$$

\section{L2. Fuzzy number}

$D L=\left\{\left(x, \mu_{D L}(x)\right) \mid x \in \mathcal{U}_{D L}=[0.5,1]\right\} \quad$ means that customers are partly loyal towards brand. Value of customer retention rate belongs to interval $[0.5,1]$. Expression of fuzzy number in trapezoidal form is $D L=[0.5,0.8,1,1]$. Membership function of fuzzy number is

$$
\mu_{D L}(x)=\left\{\begin{array}{cc}
1-\mu_{Z}(x) & 0.5<x \leq 1 \\
0 & x \leq 0.5
\end{array}\right.
$$

\section{L3. Fuzzy number}

$Z=\left\{\left(x, \mu_{Z}(x)\right) \mid x \in \mathcal{U}_{Z}=[0.2,8]\right\}$ means that customers are satisfied with the brand. This represents group of customers who take into consideration relation between costs and benefit which comes with the brand and are ready to leave the brand at any moment. Value of customer retention rate belongs to interval $[0.2,0.8]$. Expression of fuzzy number in triangular form is $Z=[0.2,0.5,0.8]$. Membership function of fuzzy number is

$$
\mu_{Z}(x)=\left\{\begin{array}{cc}
0 & 0.8 \leq x \leq 0.2 \\
\frac{10 x-2}{3} & 0.2 \leq x \leq 0.5 \\
\frac{8-10 x}{3} & 0.5 \leq x \leq 0.8
\end{array}\right.
$$

L4. Fuzzy number

$Z N=\left\{\left(x, \mu_{Z N}(x)\right) \mid x \in \mathcal{U}_{Z N}=[0,0.5]\right\} \quad$ means that customers are satisfied by habit with the brand. That is group of customers who do not analyze reasons for choosing other brand or are not able to do it because of market circumstances. Value of customer retention rate belongs to interval $[0,0.5]$. Expression of fuzzy number in trapezoidal form is $Z N=$ $[0,0,0.2,0.5]$. Membership function of fuzzy number is

$$
\mu_{Z N}(x)=\left\{\begin{array}{cc}
1-\mu_{Z}(x) & 0 \leq x \leq 0.5 \\
0 & x \geq 0.5
\end{array}\right.
$$

\section{L5. Fuzzy number}

$N L=\left\{\left(x, \mu_{N L}(x)\right) \mid x \in \mathcal{U}_{N L}=[0,0.2]\right\} \quad$ means that customers are disloyal to the brand. That is group of customers who are cost sensitive and who are not loyally to any brand. Value of customer retention rate belongs to interval $[0,0.2]$. Expression of fuzzy number in trapezoidal form is $N L=[0,0,0.2,0.2]$. Membership function of fuzzy number is

$$
\mu_{N L}(x)=\left\{\begin{array}{cc}
1 & 0 \leq x<0.2 \\
0 & x \geq 0.2
\end{array}\right.
$$

[2.] With $y$ we mark linguistic variable "perceived quality" of brand and write in form $\left(y, \mathcal{K}(y), \mathcal{U}_{2}, M_{2}\right)$.

Value area which variable $y$ can absorb we define as fuzzy set family.

$$
\begin{gathered}
\mathcal{K}(y)=\{\text { very bad, partially bad, good, very good, apsolutely good }\} \\
=\{V L, D L, D, V D, A D\}=\left\{K_{1}, K_{2}, K_{3}, K, K_{5}\right\}=\left\{\left(y, \mu_{K_{i}}(y)\right) \mid y \in K_{i}, K_{i} \subseteq \mathcal{U}_{2}\right\}, i=\overline{1,5} .
\end{gathered}
$$

Area to which fuzzy set domains $K_{i}$ belong to is $\mathcal{U}_{2}=$ $[0,1]$ and represents value interval of reclamation index $s_{r}$ of the product. Semantic function $M_{2}: \mathcal{U}_{2} \rightarrow \mathcal{K}(y)$ is triangular, trapezoidal or $\Gamma$ membership function and is marked with $\mu_{K_{i}}(y)$. Fuzzy numbers of family $\mathcal{K}(y)$ have following meaning, membership function in relation to domain value and described constructive approach, and graphical representation of fuzzy numbers is given in Figure 3.

$\mathrm{K} 1$. Fuzzy number

$V L=\left\{\left(y, \mu_{V L}(y)\right) \mid y \in \mathcal{U}_{V L}=[0.8,1]\right\} \quad$ means that perceived quality of brand is very bad and customers are not satisfied with the brand quality. In this case product's reclamation rate $s_{r}$, is in interval $[0.8,1]$ i. e $\left(0.8 \leq s_{r} \leq 1\right)$. Fuzzy number membership function $\mathrm{VL}=[0.8,0.8,1,1]$ is as follows

$$
\mu_{V L}(y)=\left\{\begin{array}{cc}
1, & 0.8 \leq y \leq 1 \\
0, & y<0.8
\end{array}\right.
$$

$D L=\left\{\left(y, \mu_{D L}(y)\right) \mid y \in \mathcal{U}_{D L}=[0.5,1]\right\} \quad$ means that customers evaluated brand perceived quality as partly bad and negative experience with the brand prevail. In this case product's reclamation rate is in interval $[0.5,1]$. Fuzzy number membership function $\mathrm{DL}=[0.5,0.8,1,1]$ is as follows

$$
\mu_{D L}(y)=\left\{\begin{array}{cc}
1-\mu_{D}(y) & 0.5<y \leq 1 \\
0 & y \leq 0.5
\end{array}\right.
$$

\section{K3.Fuzzy number}

$D=\left\{\left(y, \mu_{D}(y)\right) \mid y \in \mathcal{U}_{D}=[0.2,8]\right\}$ means that customers evaluated brand perceived quality as good and mostly are satisfied with the brand. Reclamation rate $s_{r}$ is in interval [0.2, $0.8]$. Fuzzy number membership function $D=[0.2,0.5,0.8]$ is as follows

K2.Fuzzy number 


$$
\mu_{D}(y)=\left\{\begin{array}{cc}
0 & 0.8 \leq y \leq 0.2 \\
\frac{10 y-2}{3} & 0.2 \leq y \leq 0.5 \\
\frac{8-10 y}{3} & 0.5 \leq y \leq 0.8
\end{array}\right.
$$

K4 Fuzzy number

$V D=\left\{\left(y, \mu_{V D}(y)\right) \mid y \in \mathcal{U}_{V D}=[0,0.5]\right\} \quad$ means that customers evaluated brand perceived quality as very good, therefore there are many more satisfied customers with the brand than dissatisfied. Reclamation rate $s_{r}$ is in interval [0, $0.5]$. Fuzzy number membership function $V D=[0,0,0.2,0.5]$ is as follows

$$
\mu_{V D}(y)=\left\{\begin{array}{cc}
1-\mu_{D}(y) & 0 \leq y<0.5 \\
0 & y \geq 0.5
\end{array}\right.
$$

\section{K5. F uzzy number}

$A D=\left\{\left(z, \mu_{A D}(z)\right) \mid z \in \mathcal{U}_{A D}=[0,0.2]\right\} \quad$ means that customers evaluated brand perceived quality as absolutely good and these customers are mostly satisfied with the brand. Reclamation rate is in interval $\left(0 \leq s_{r} \leq 0.2\right)$. Fuzzy number membership function $A D=[0,0,0.2,0.2]$ is as follows

$$
\mu_{A D}(y)=\left\{\begin{array}{cc}
1 & 0 \leq y<0.2 \\
0 & y \geq 0.2
\end{array}\right.
$$

[3.] With $z$ we label linguistic variable brand familiarity which is written in $\left(z, \mathcal{P}(z), \mathcal{U}_{3}, M_{3}\right)$. Variable value space is defined by fuzzy set family

$$
\begin{aligned}
\mathcal{P}(z) & =\{\text { brand is not well known, familiar with reminder, spontaneously familiar }\} \\
= & \{B N, P P, S P\}=\left\{P_{1}, P_{2}, P_{3}\right\}=\left\{\left(z, \mu_{P_{i}}(z)\right) \mid z \in P_{i}, P_{i} \subseteq \mathcal{U}_{3}\right\}, i=1,2,3 .
\end{aligned}
$$

Fuzzy set domain of area $P_{i}$ is interval of value rate of brand familiarity $\mathcal{U}_{3}=[0,1]$ and semantic function $\mathcal{M}_{3}: \mathcal{P}(z) \rightarrow \mathcal{U}_{3}$ is membership function $\mu_{P_{i}}(z)$ defined by triangular or trapezoidal form. Graphical representation of fuzzy numbers family $\mu_{P_{i}}(z)$ is given in Figure 3 .

P1 Fuzzy number

$B N=\left\{\left(z, \mu_{B N}(z)\right) \mid z \in \mathcal{U}_{B N}=[0,0.5]\right\}$ means that brand is unfamiliar on the market and most of the respondents are not able to remember the brand even when reminded. Rate value of brand familiarity $s_{p p}$ belongs to interval $[0,0.5]$. Membership function of fuzzy number $B N=[0,0,0.2,0.5]$ is as follows

$$
\mu_{B N}(z)=\left\{\begin{array}{cc}
1-\mu_{P P}(z) & 0 \leq z \leq 0.5 \\
0 & z \geq 0.5
\end{array}\right.
$$

\section{P2. Fuzzy number}

$P P=\left\{\left(z, \mu_{P P}(z)\right) \mid z \in \mathcal{U}_{P P}=[0.2,0.8]\right\}$ means that brand is familiar with reminder the and customers are able to remember brand with previous reminder. Rate value of brand familiarity $s_{p p}$ belongs to interval $[0.2,0.8]$ and fuzzy number membership function $P P=[0.2,0.5,0.8]$ is as follows

$$
\mu_{P P}(z)=\left\{\begin{array}{cc}
0 & 0.8 \leq z \leq 0.2 \\
\frac{10 z-2}{3} & 0.2 \leq z \leq 0.5 \\
\frac{8-10 z}{3} & 0.5 \leq z \leq 0.8
\end{array}\right.
$$

\section{P3. Fuzzy number}

$S P=\left\{\left(z, \mu_{S P}(z)\right) \mid z \in \mathcal{U}_{S P}=[0.5,1]\right\}$ means that brand is spontaneously familiar and customers are able to remember the brand without previous reminder. Rate value of brand familiarity $s_{p p}$ belongs to interval $[0.5,1]$ and fuzzy number membership function $\mathrm{SP}=[0.5,0.8,1,1]$ is as it follows

$$
\mu_{S P}(z)=\left\{\begin{array}{cc}
1-\mu_{P P}(z) & 0.5 \leq z \leq 1 \\
0 & z \leq 0.5
\end{array}\right.
$$

[4.] Based on defined quantitative evaluation association related to brand we define fuzzy numbers that describe linguistic variable. We label variable brand association with t, which is written in for $\left(t, \mathcal{A}(t), \mathcal{U}_{4}, M_{4}\right)$. Fuzzy numbers space is defined with fuzzy set family

$$
\begin{gathered}
\mathcal{A}(t)=\{\text { associations negative, association neither positive or negative, associations positive }\} \\
=\{A N, P N, A P\}=\left\{A_{1}, A_{2}, A_{3}\right\}=\left\{\left(t, \mu_{A_{i}}(t)\right) \mid t \in A_{i}, A_{i} \subseteq \mathcal{U}_{4}\right\}, i=1,2,3 .
\end{gathered}
$$

Fuzzy numbers of family $\mathcal{A}(t)$ given in triangular form have meaning in regards to domain value:

\section{A1. Fuzzy number}

$A N=\left\{\left(t, \mu_{A N}(t)\right) \mid t \in U_{A N}=[0,0.5]\right\} \quad$ means that customers prefer negative associations with the brand. Therefore most of the interviewed customers link their relations with the brand with negatively preferred experience, so further relationship is valid $s_{p p} \leq s_{n p}$. Membership function of fuzzy number $A N=[0,0,0.2,0.5]$ is

$$
\mu_{A N}(t)=\left\{\begin{array}{cc}
1-\mu_{P N}(t) & 0 \leq t<0.5 \\
0 & t \geq 0.5
\end{array}\right.
$$

\section{A2. Fuzzy number}

$P N=\left\{\left(t, \mu_{P N}(t)\right) \mid t \in U_{P N}=[0.2,0.8]\right\}$ means that neither negative nor or positive preferences related to the brand experience prevail with customer. In this case rate of positively preferred experiences is closely equal to rate of negatively preferred experiences, wich is whu relationship is valid $s_{p p} \approx s_{n p}$. Membership function of fuzzy number $P N=[0.2$, $0.5,0.8]$ is

$$
\mu_{P N}(t)=\left\{\begin{array}{cc}
0 & 0.8 \leq t \leq 0.2 \\
\frac{10 t-2}{3} & 0.2 \leq t \leq 0.5 \\
\frac{8-10 t}{3} & 0.5 \leq t \leq 0.8
\end{array}\right.
$$




\section{A3.Fuzzy number}

$A P=\left\{\left(t, \mu_{A P}(t)\right) \mid t \in U_{A P}=[0.5,1]\right\}$ means that customers mostly prefer positive association with the brand. Rate of positively preferred experiences is drastically higher than rate of negatively preferred experiences, therefore further relationship is valid $s_{p p} \geq s_{n p}$. Membership function of fuzzy number $A P=[0.5,0.8,1,1]$ is

$$
\mu_{A P}(t)=\left\{\begin{array}{cc}
1-\mu_{P N}(t) & 0.5 \leq t<1 \\
0 & t \leq 0.5
\end{array}\right.
$$

Graphical representation of fuzzy numbers family $\mathcal{A}(t)$ is given in Figure 3. What is left is to model output variable brand market value.

\section{Modeling of Output Variables of Fuzzy Number Family}

The result of market brand value evaluation in defined is such a way which enables interpretation of market brand value evaluation results for four criteria used. Market brand value is linguistic value evaluated by five qualitative states, defined in interval $U=[0,1]$. That is, let it be that value space which output variable $u \equiv$ brand market value marked as $(u, \mathcal{T}(u), \mathcal{U}, \mathcal{M})$ qualified by fuzzy number family set $\mathcal{T}(u)$ is

$$
\begin{gathered}
\mathcal{T}(u)=\{\text { very low, low, good, high, very high }\} \\
=\{V S, S, D, V, V V\}=\left\{T_{1}, T_{2}, T_{3}, T_{4}, T_{5}\right\} \\
=\left\{\left(u, \mu_{T_{i}}(u)\right) \mid u \in T_{i}, T_{i} \subseteq \mathcal{U}\right\}, i=1,2,3,4,5
\end{gathered}
$$

Individually fuzzy numbers represent quantitative state of market brand value with further meaning (Table 1);

Table 1. Quantitative state brand market and meaning.

\begin{tabular}{ll}
\hline Quantitative state & Meaning \\
\hline $\mathrm{VS} \equiv$ very low & market brand value must be improved quickly \\
$\mathrm{S} \equiv$ low, & market brand value can be improved \\
$\mathrm{D} \equiv$ good & $\begin{array}{l}\text { improvement of market brand value is possible, but } \\
\text { not necessary } \\
\mathrm{V} \equiv \text { high }\end{array}$ \\
$\mathrm{mV} \equiv$ very high & $\begin{array}{l}\text { there is no need for changes, it is important to keep } \\
\text { acquired market brand value. }\end{array}$ \\
\hline
\end{tabular}

Quantitative states which are used to evaluate market brand value are given in form of triangular fuzzy numbers with membership function, respectively (Figure 4).

Fuzzy number $V S=\left\{\left(u, \mu_{V S}(u)\right) \mid u \in \mathcal{U}_{1}=[0,0.25]\right\}$ with membership function

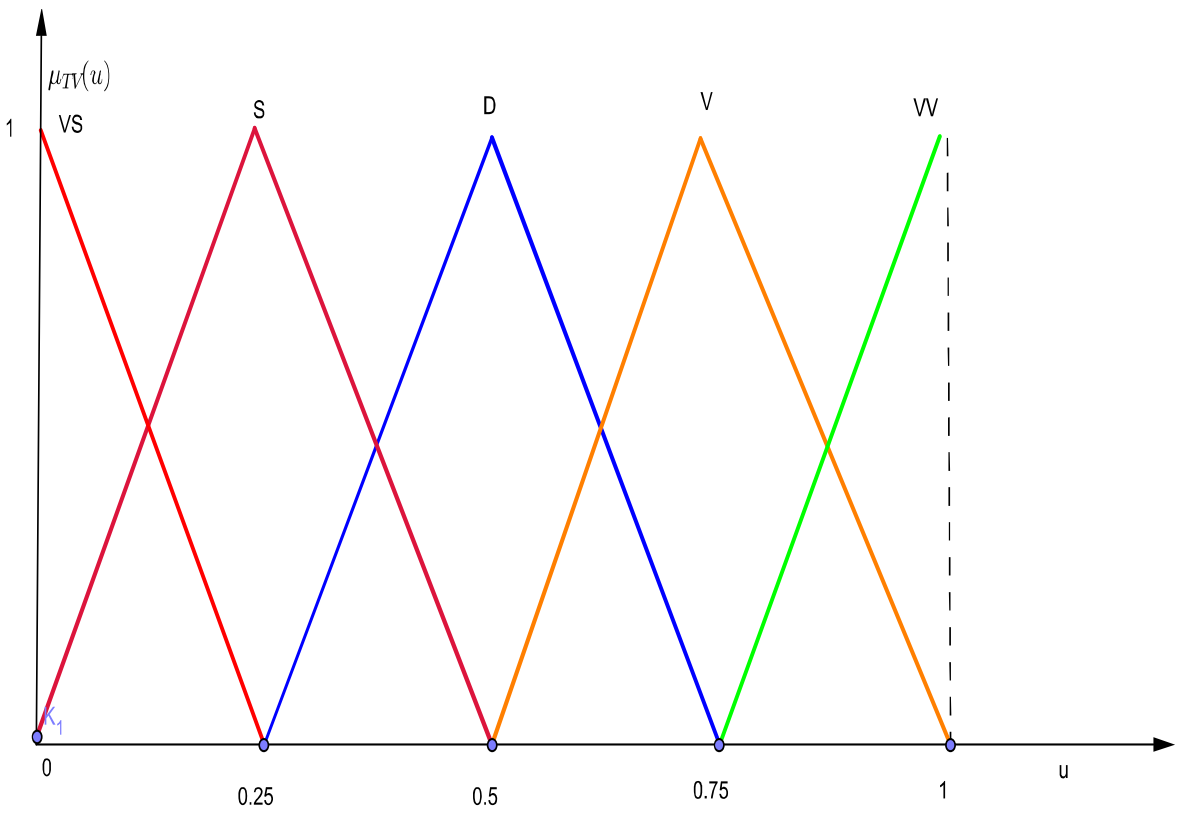

Figure 4. Membership function fuzzy number VS, S, D, V, VV brand market evaluation.

$$
\mu_{V S}(u)=\left\{\begin{array}{cc}
1 & \text { for } u=0 \\
0 & \text { for } u \geq 0.25 \\
1-\frac{u}{0.25} & \text { for } 0 \leq u \leq 0.25
\end{array}\right.
$$

Fuzzy number $S=\left\{\left(u, \mu_{S}(u)\right) \mid u \in \mathcal{U}_{2}=[0,0.5]\right\}$

with membership function

$$
\mu_{S}(u)=\left\{\begin{array}{cc}
0 & \text { for } 0.5 \leq u \leq 0 \\
\frac{u}{0.25} & \text { for } 0 \leq u \leq 0.25 \\
2-\frac{u}{0.25} & \text { for } 0.25 \leq u \leq 0.5
\end{array}\right.
$$

Fuzzy number

$$
D=\left\{\left(u, \mu_{D}(u)\right) \mid u \in \mathcal{U}_{3}=[0.25,0.75]\right\}
$$

with membership function

$$
\mu_{D}(u)=\left\{\begin{array}{cc}
0 & \text { for } 0.75 \leq u \leq 0.25 \\
\frac{u}{0.25}-1 & \text { for } 0.25 \leq u \leq 0.5 \\
1-\frac{u}{0.25} & \text { for } 0.5 \leq u \leq 0.75
\end{array}\right.
$$

Fuzzy number 


$$
V=\left\{\left(u, \mu_{V}(u)\right) \mid u \in \mathcal{U}_{4}=[0.5,1]\right\}
$$

with membership function

$$
\mu_{V}(u)=\left\{\begin{array}{cc}
0 & \text { for } 1 \leq u \leq 0.5 \\
\frac{u}{0.25}-2 & \text { for } 0.5 \leq u \leq 0.75 \\
1-\frac{u}{0.25} & \text { for } 0.75 \leq u \leq 1
\end{array}\right.
$$

Fuzzy number

$$
V V=\left\{\left(u, \mu_{V V}(u)\right) \mid u \in U_{5}=[0.75,1]\right\}
$$

with membership function

$$
p_{i} \wedge q_{j} \wedge r_{k} \wedge w_{l} \wedge \omega_{n}=\min \left(\mu_{L_{i}}(x), \mu_{K_{j}}(y), \mu_{P_{k}}(z), \mu_{A_{l}}(t), \mu_{T_{n}}(u)\right)
$$

Where $\omega_{n}=\omega_{i j l k}, i, k=1,2,3,4,5 ; j, l=1,2,3$ and following four members

$$
(x, y, z, t, u) \subset \mathcal{L} \times \mathcal{K} \times \mathcal{P} \times \mathcal{A} \times \mathcal{T} \subset \mathcal{U}_{1} \times \mathcal{U}_{2} \times \mathcal{U}_{3} \times \mathcal{U}_{4} \times \mathcal{U}
$$

Example 1. Rule R1: If rate of loyalty $\mathrm{L}$ of brand customers is (NL) and rate of perceived quality $\mathrm{K}$ of brand is (VD) and rate of familiarity (P) of brand is (BN) and associations (A) related towards brand is (AP) then brand market value is very low (VS). According to our labels it can be written as follows:

If $[(x$ is $N L)$ and ( $y$ is VD) and ( $\mathrm{z}$ is $\mathrm{BN})$ and $(\mathrm{t}$ is $\mathrm{AP})]$ then $\mathrm{u}$ is VS or in form

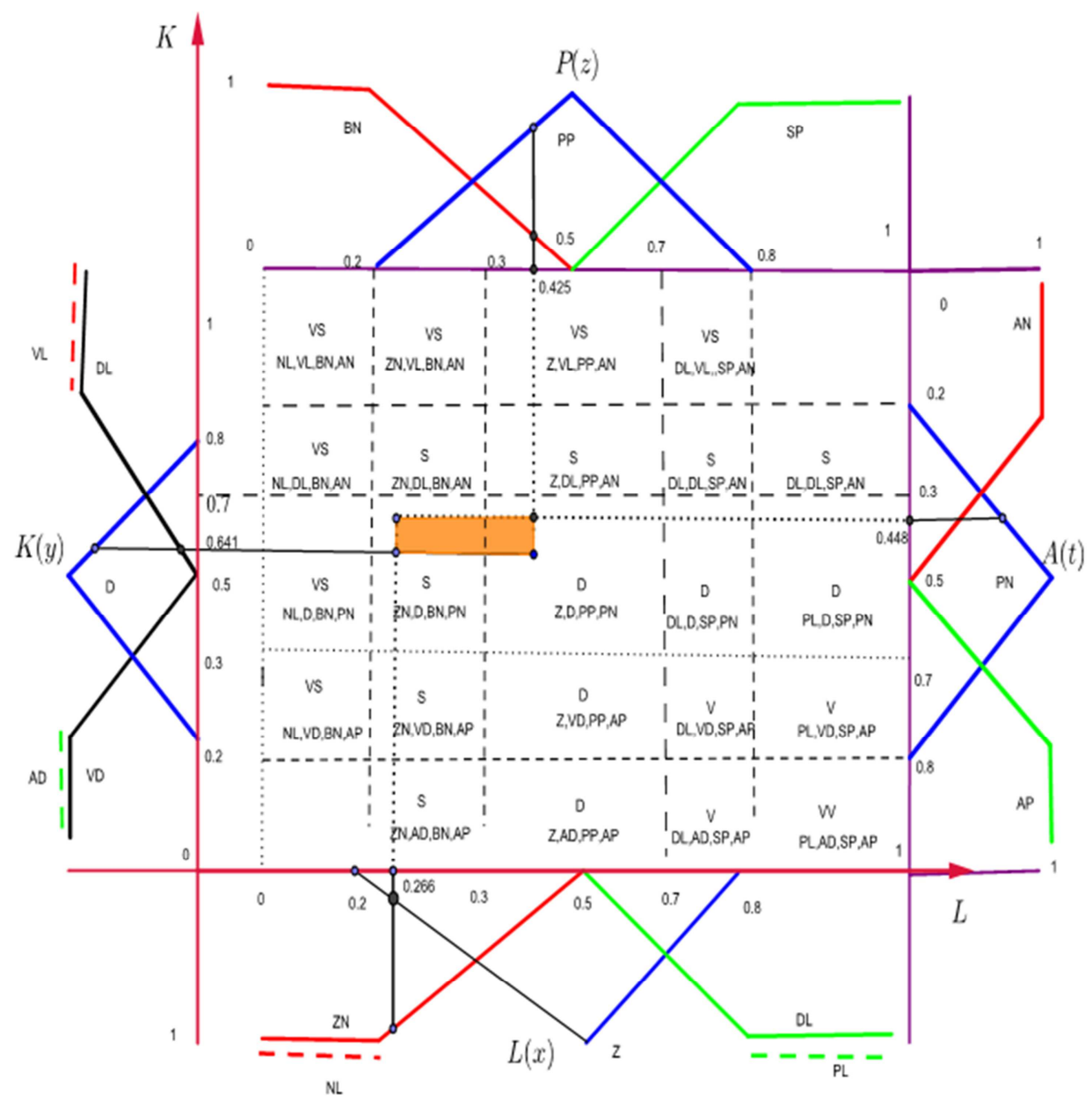

Figure 5. Graphical representation in construction If-Then rules of conclusion.

$p \wedge q \wedge r \wedge w \wedge \omega=\min \left(\mu_{N L}(x), \mu_{V D}(y), \mu_{B N}(z), \mu_{A P}(t), \mu_{V S}(u)\right)$ 
Let's construct graphically the fuzzy four $(L, K, P, A)$ by which are defined possible states of output variables labels (Figure 5) and based on them we will form inference rules

[R1:] IF ( $x$ is NL and $y$ is VL and $z$ is $B N$ and $t$ is $A N$ ) OR ( $x$ is $N L$ and $y$ is DL and $z$ is $B N$ and $t$ is $A N$ ) OR ( $x$ is NL and $y$ is $V D$ and $z$ is $B N$ and $t$ is AP) OR ( $x$ is NL and $y$ is $D$ and $z$ is $\mathrm{BN}$ and $\mathrm{t}$ is $\mathrm{PN}$ ) OR ( $\mathrm{x}$ is $\mathrm{ZN}$ and $\mathrm{y}$ is $\mathrm{VL}$ and $\mathrm{z}$ is $\mathrm{BN}$ and $\mathrm{t}$ is $\mathrm{AN}$ ) OR ( $\mathrm{x}$ is $\mathrm{Z}$ and $\mathrm{y}$ is VL and $\mathrm{z}$ is $\mathrm{PP}$ and $\mathrm{t}$ is $\mathrm{AN}$ )

$\mathrm{OR}$ ( $\mathrm{x}$ is DL and $\mathrm{y}$ is VL and $\mathrm{z}$ is $\mathrm{SP}$ and $t$ is $\mathrm{AN}$ )

THEN $u$ is VS

[R2:] IF ( $\mathrm{x}$ is $\mathrm{ZN}$ and $\mathrm{y}$ is $\mathrm{VD}$ and $\mathrm{z}$ is $\mathrm{BN}$ and $\mathrm{t}$ is $\mathrm{AP}$ )

$\mathrm{OR}$ ( $\mathrm{x}$ is $\mathrm{ZN}$ and $\mathrm{y}$ is $\mathrm{D}$ and $\mathrm{z}$ is $\mathrm{BN}$ and $t$ is $\mathrm{PN}$ )

$\mathrm{OR}$ ( $\mathrm{x}$ is $\mathrm{ZN}$ and $\mathrm{y}$ is $\mathrm{DL}$ and $\mathrm{z}$ is $\mathrm{BN}$ and $\mathrm{t}$ is $\mathrm{AN}$ )

$\mathrm{OR}$ ( $\mathrm{x}$ is $\mathrm{ZN}$ and $\mathrm{y}$ is $\mathrm{AD}$ and $\mathrm{z}$ is $\mathrm{BN}$ and $\mathrm{t}$ is $\mathrm{AP}$ )

OR ( $x$ is $Z$ and $y$ is DL and $z$ is PP and $t$ is $A N$ )

OR ( $x$ is DL and $y$ is DL and $z$ is $\mathrm{SP}$ and $t$ is $A N$ )

THEN $u$ is $\mathrm{S}$

[R3:] IF ( $x$ is $Z$ and $y$ is $A D$ and $z$ is $P P$ and $t$ is AP)

OR ( $x$ is $Z$ and $y$ is VD and $z$ is PP and $t$ is AP)

OR ( $x$ is $Z$ and $y$ is $D$ and $z$ is PP and $t$ is $P N$ )

OR ( $x$ is DL and $y$ is $D$ and $z$ is SP and $t$ is PN)

OR ( $x$ is PL and $y$ is $D$ and $z$ is SP and $t$ is PN)

THEN $u$ is $D$

[R4:]IF ( $x$ is DL and $y$ is VD and $z$ is SP and $t$ is AP)

OR ( $x$ is $P L$ and $y$ is VD and $z$ is SP and $t$ is AP)

$\mathrm{OR}$ ( $\mathrm{x}$ is DL and $\mathrm{y}$ is $\mathrm{AD}$ and $\mathrm{z}$ is $\mathrm{SP}$ and $\mathrm{t}$ is $\mathrm{AP}$ )

$$
\begin{gathered}
\mu_{L_{i}}\left(s_{z}^{0}\right), \mu_{L_{i+1}}\left(s_{z}^{0}\right), \mu_{K_{j}}\left(s_{r}^{0}\right), \mu_{K_{j+1}}\left(s_{r}^{0}\right) \mu_{P_{k}}\left(s_{p}^{0}\right), \\
\mu_{P_{k+1}}\left(s_{p}^{0}\right), \mu_{A_{l}}\left(s_{p p}^{0}\right), \mu_{A_{l+1}}\left(s_{p p}^{0}\right)
\end{gathered}
$$

i. $j=1,2,3,4,5 ; k, l=1,2,3$ respectively.

Strength of constructed rules is:

$$
\begin{aligned}
& \alpha_{i, j, k, l}=\left(\mu_{L_{i}}\left(s_{z}^{0}\right) \wedge \mu_{K_{j}}\left(s_{r}^{0}\right) \wedge \mu_{P_{k}}\left(s_{p}^{0}\right) \wedge \mu_{A_{l}}\left(s_{p p}^{0}\right)\right) \\
& =\min \left(\mu_{L_{i}}\left(s_{Z}^{0}\right), \mu_{K_{j}}\left(s_{r}^{0}\right), \mu_{P_{k}}\left(s_{p}^{0}\right), \mu_{A_{l}}\left(s_{p p}^{0}\right)\right) \\
& \alpha_{i, j, k, l+1}=\left(\mu_{L_{i}}\left(s_{z}^{0}\right) \wedge \mu_{K_{j}}\left(s_{r}^{0}\right) \wedge \mu_{P_{k}}\left(s_{p}^{0}\right) \wedge \mu_{A_{l+1}}\left(s_{p p}^{0}\right)\right) \\
& =\min \left(\mu_{L_{i}}\left(s_{z}^{0}\right), \mu_{K_{j}}\left(s_{r}^{0}\right), \mu_{P_{k}}\left(s_{p}^{0}\right), \mu_{A_{l+1}}\left(s_{p p}^{0}\right)\right) \\
& \alpha_{i+1, j+1, k+1, l+1}=\left(\mu_{L_{i+1}}\left(s_{z}^{0}\right) \wedge \mu_{K_{j+1}}\left(s_{r}^{0}\right) \wedge \mu_{P_{k+1}}\left(s_{p}^{0}\right) \wedge \mu_{A_{l+1}}\left(s_{p p}^{0}\right)\right) \\
& =\min \left(\mu_{L_{i+1}}\left(s_{z}^{0}\right), \mu_{K_{j+1}}\left(s_{r}^{0}\right), \mu_{P_{k+1}}\left(s_{p}^{0}\right), \mu_{A_{l+1}}\left(s_{p p}^{0}\right)\right)
\end{aligned}
$$

For each rule we have one control output variable determined by conjunction of rule's strength and fuzzy sets of output variable, for example for first case it is

$$
\alpha_{i, j, k, l} \wedge \mu_{T_{n}}\left(u_{0}\right)=\min \left(\alpha_{i, j, k, l}, \mu_{T_{n}}\left(u_{0}\right)\right)
$$

We receive one output variable out of these control output variables, by aggregation technique based on maximum operator,.

$$
\mu_{a g g}\left(u_{0}\right)=\max \left\{\alpha_{i, j, k, l} \wedge \mu_{T_{i, j, k, l}}\left(u_{0}\right), \ldots, \ldots, \alpha_{i+1, j+1, k+1, l+1} \wedge \mu_{T_{i+1, j+1, k+1, l+1}}\left(u_{0}\right)\right.
$$




$$
=\max \left\{\min \left(\alpha_{i, j, k, l}, \mu_{T_{i, j, k, l}}\left(u_{0}\right)\right), \min \left(\alpha_{i, j, k, l+1}, \mu_{T_{i, j, k, l+1}}\left(u_{0}\right)\right), \ldots, \ldots, \ldots, \min \left(\alpha_{i+1, j+1, k+1, l+1}, \mu_{T_{i+1, j+1, k+1, l+1}}\left(u_{0}\right)\right)\right.
$$

In order to get unique output variable in terms of brand market value it is necessary to conduct defuzzification. That is to decode function $\mu_{a g g}\left(u_{0}\right)$. There are many methods, and we use center of gravity method for continuos fuzzy sets, [20]

$$
u_{T V}^{*}=\frac{\int \sum_{k=1}^{n} \mu_{C_{k}}(u) d u}{\int \sum_{k=1}^{n} \mu_{C_{k}}(u) d u}
$$

Let's test technique of market brand value evaluation on hypothetical example.

Example 2. For the needs of evaluation brand market value of company "XZY Trade" are measured by brand indicator were measured rate and after conducted analysis further values of rates were received

-customer loyalty towards brand measured by satisfaction rate, result is $S_{z}=0.266$,

-perceived quality of brand measured by reclamation rate, result is $s_{r}=0.641$,

-brand familiarity measured by familiarity rate, result is $s_{p}=0.425$,

-brand associations measured by positive experience rate, result is $s_{p p}=0.448$ (Figure 5).

$$
\begin{aligned}
& \alpha_{1}=\min \left(\mu_{Z}\left(s_{Z}^{0}\right), \mu_{D}\left(s_{r}^{0}\right), \mu_{B N}\left(s_{p}^{0}\right), \mu_{A N}\left(s_{p p}^{0}\right)\right)=\min (0.22,0.53,0.25,0.173)=0.173 \\
& \alpha_{2}=\min \left(\mu_{Z}\left(s_{z}^{0}\right), \mu_{D}\left(s_{r}^{0}\right), \mu_{B N}\left(s_{p}^{0}\right), \mu_{P N}\left(s_{p p}^{0}\right)\right)=\min (0.22,0.53,0.25,0.73)=0.22 \\
& \alpha_{16}=\min \left(\mu_{N L}\left(s_{z}^{0}\right), \mu_{D L}\left(s_{r}^{0}\right), \mu_{P P}\left(s_{p}^{0}\right), \mu_{P N}\left(s_{p p}^{0}\right)\right)=\min (0.78,0.47,0.75,0.827)=0.47
\end{aligned}
$$

One control output variable corresponds for each rule which is based on a conjunction $\alpha_{i, j, k, l} \wedge \mu_{T V}(u)=\min \left(\alpha_{i}, \mu_{T V}(u)\right), i=1,2, \ldots, 16$ which in this case are

$$
\begin{gathered}
\alpha_{1} \wedge \mu_{S}(u)=\min \left(0.173, \mu_{S}(u)\right), \\
\alpha_{2} \wedge \mu_{S}(u)=\min \left(0.22, \mu_{S}(u)\right), \\
\alpha_{3} \wedge \mu_{S}(u)=\min \left(0.173, \mu_{S}(u)\right), \ldots, \\
, \ldots \alpha_{12} \wedge \mu_{D}(u)=\min \left(0.53, \mu_{D}(u)\right), \ldots ., \\
\alpha_{16} \wedge \mu_{D}(u)=\min \left(0.47, \mu_{D}(u)\right)
\end{gathered}
$$

We constructed fuzzy set of output variable based on individual values of output variables. Graphical representation of polygon which represents membership function of output fuzzy set is given in Figure 6 which is obtained by testing the algorithm in MATLAB software (Figure 7a, 7b). 


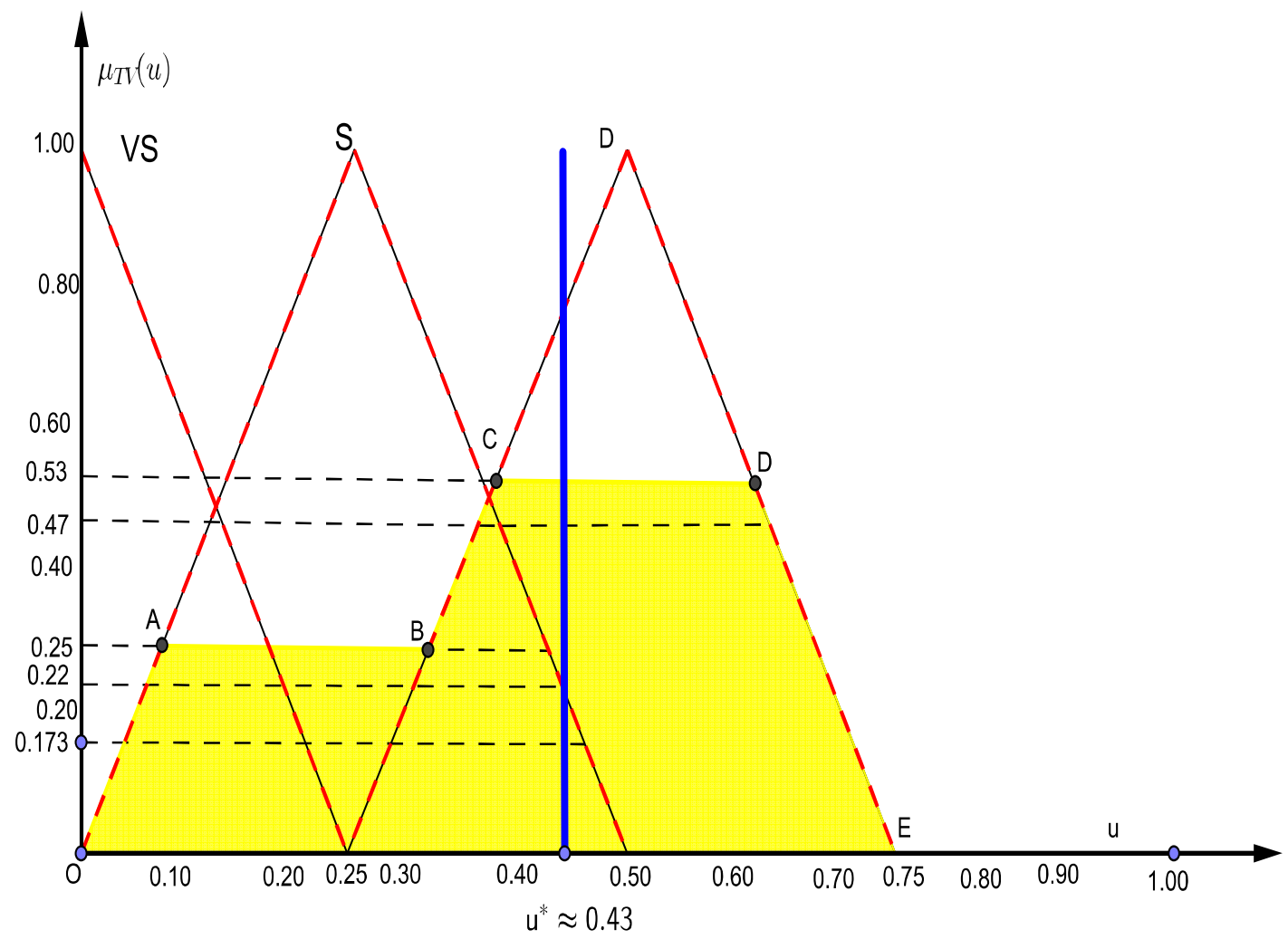

Figure 6. Membership function output fuzzy sets.

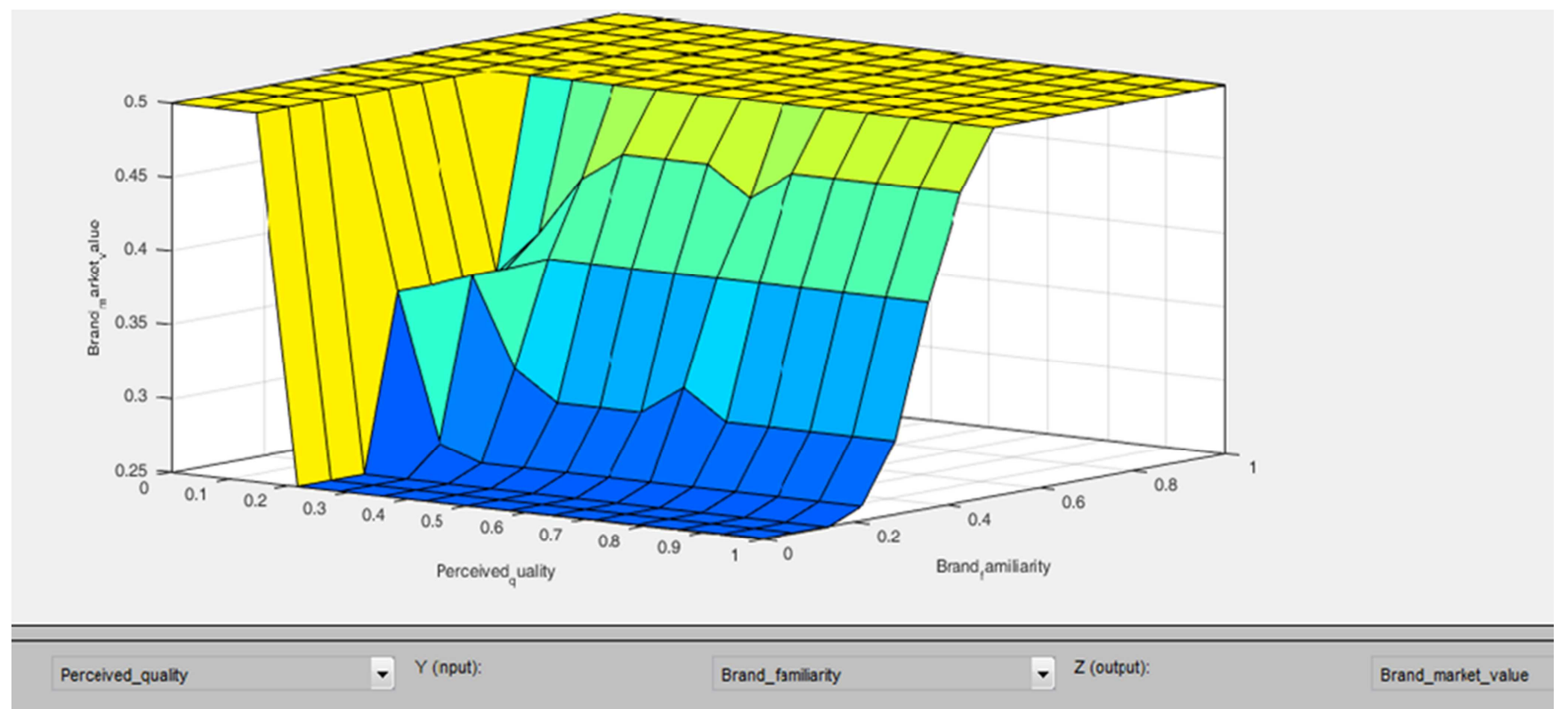




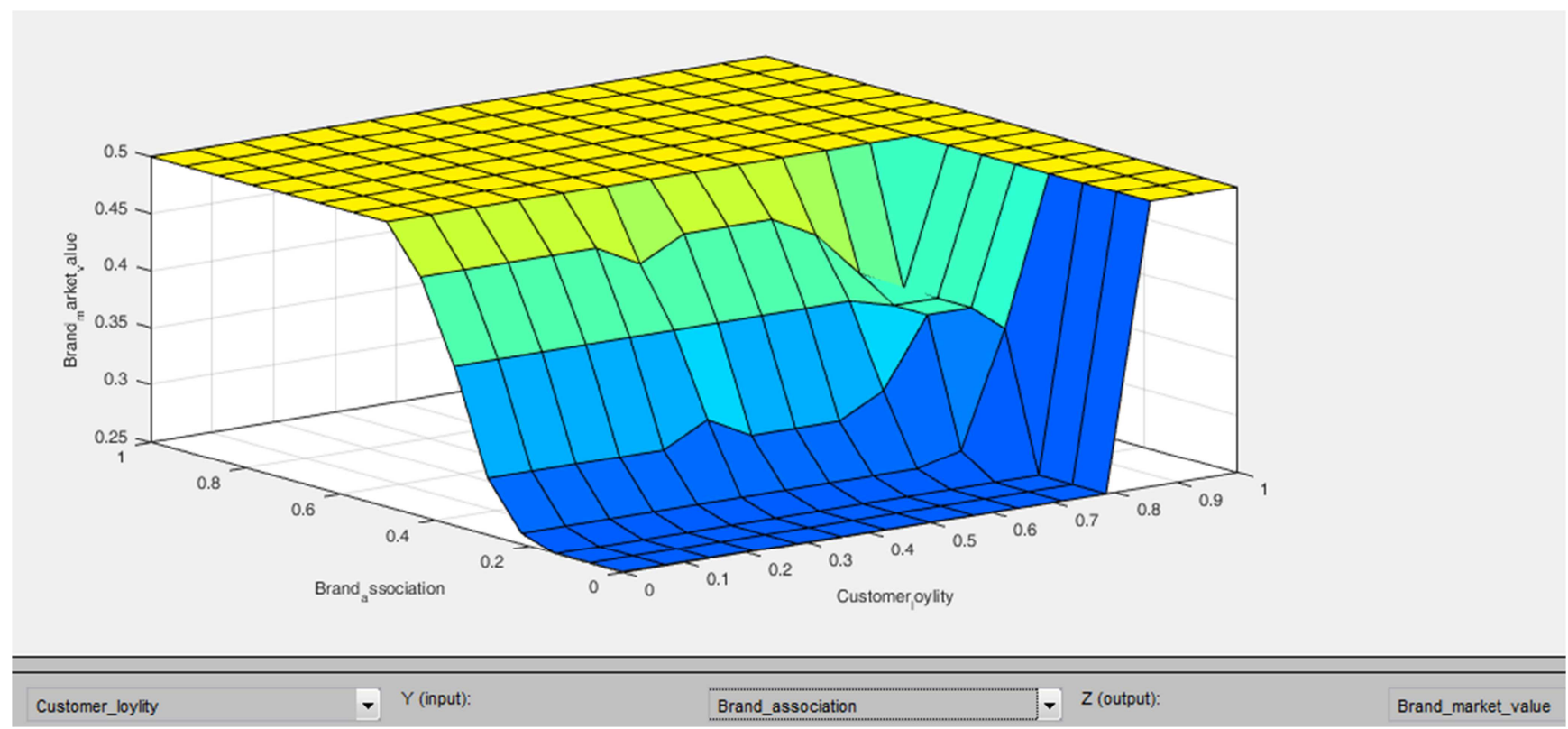

b

Figure 7. Dependency function TV. a: dependency function TV of "perceived quality" (K) and "brand familiarity" $(P), T V=f(K, P)$. b: dependency function TV of "brand association" (A) and "customer lojality" ( $L), T V=f(A, L$, in example).

Membership function of total fuzzy set of market brand value agge $=T V$ in analytical form is

$$
\mu_{\text {agge }(u)}=\left\{\begin{array}{c}
\frac{u}{0.25}, 0 \leq u \leq 0.0625 \\
0.25,0.0625 \leq u \leq 0.3125 \\
\frac{u}{0.25}-1,0.3125 \leq u \leq 0.382 \\
0.53,0.382 \leq u \leq 0.6175 \\
3-\frac{u}{0.25}, 0.6175 \leq u \leq 0.75
\end{array}\right.
$$

What is left is to determine one value (singleton) $u^{*}$ of market brand value rate. For this purpose we use defuzzification method. Mostly we choose value that represents center of gravity. By implementation of center of gravity method in our case we can see that coordinate points $\mathrm{A}$, $\mathrm{B}, \mathrm{C}, \mathrm{D}, \mathrm{E}$, are as follows: A $(0.0625,0.25), \mathrm{B}(0.3125,0.25)$, $\mathrm{C}(0.382,0.53), \mathrm{D}(0.6175,0.53), \mathrm{E}(0.75,0)$, (Figure 6). Center of gravity for continuous fuzzy set is calculate by using rule:

$$
u^{*}=\frac{\text { Numerator }}{\text { Denumarator }}=\frac{\int \cdot \sum_{k=1}^{n} \mu_{C_{k}}(u) d u}{\int \sum_{k=1}^{n} \mu_{C_{k}}(u) d u}
$$

Let us first calculate Numerator value by using graphical representation of output fuzzy set (Figure 6) and membership function of output set.

$$
\text { Numerator }=\int_{0}^{0.0625} \frac{u^{2}}{0.25} d u+\int_{0.0625}^{0.3125} 0.25 u d u+\int_{0.3125}^{0.382}\left(\frac{u}{0.25}-1\right) u d u+\int_{0.382}^{0.6175} 0.53 u d u+
$$

$+\int_{0.6175}^{0.75} u\left(3-\frac{u}{0.25}\right) d u=0.0003254+0.0117135++0.0336337-0.0241339+0.0623761+0.2717907-0.24855=$

\subsection{6}

Denominator value

$$
\begin{gathered}
\text { Demerator }=\int_{0}^{0.0625} \frac{u}{0.25} d u+\int_{0.0625}^{0.3125} 0.25 d u+\int_{0.3125}^{0.382}\left(\frac{u}{0.25}-1\right) d u+\int_{0.382}^{0.6175} 0.53 d u+ \\
+\int_{0.6175}^{0.75}\left(3-\frac{u}{0.25}\right) d u=0.00781124+0.06475+0.02703+0.124815+0.035112=0.259524
\end{gathered}
$$

Required output value is

$$
u^{*}=\frac{\text { Numerator }}{\text { Denumarator }}=\frac{0.1100646}{0.259524}=0.4263 \approx 0.43
$$

Based on calculated output value rate $u^{*} \approx 0.43$ brand market value with significance level $\alpha=0.05$ confidence interval of market brand value $\pi_{u}$ of basic set is $0.25 \leq \pi_{u^{*}} \leq$
0.61. Based on that interval and evaluation criteria of market brand value we can formulate marketing and managerial decisions regarding the increase of the brand value.

\section{Conclusion}

Classical way of evaluation of market brand value based on evaluated values of indicator indices $(\mathrm{L}=$ loyalty, $\mathrm{K}=$ perceived 
quality, $\mathrm{P}=$ brand familiarity, $\mathrm{A}=$ brand association) doesn't provide possibility of quantitative expression of that evaluation therefor it is left for expert to evaluate brand market value based on evaluated indicator values. Considered model provides possibility of quantitative market brand evaluation together with more demanding confidence interval, based on evaluated indicators ( $\mathrm{L}, \mathrm{K}, \mathrm{P}, \mathrm{A}$ ).Implementing fuzzy logic and fuzzy numbers into modeling of brand value decreases:

1) insecurity of evaluation of indicator rate generated by subjectivity of examinee, in this model that value is switched by fuzzy numbers.

2) subjectivity of expert during evaluation of market brand value, because evaluation is based on values of index indicators. In this method, using if-then" defined rules, evaluation is a result of analysis of possible states which generate values of index indicators.

Advantage of this method lies in ability to use evaluated market brand value based on sample in order to evaluate market brand value based on entire population of customers in specific area (Total TV). If financial estimation of consumption per customer is familiar then it is easy to evaluate financial market brand valueon the market.

\section{References}

[1] Poliščuk, E., J., (2004) Ekspertni sistemi, ETF, Podgorica.

[2] M. Čupić, B. D. Bašić, M. Golub, (2013), Neizrazito, evolucijsko i neuroračunarstvo, Zagreb.

[3] Z. Kovačević S. Bogdan, (2000), Inteligentno upravljanje sustavima, Fakultet elektrotehnike i računarstva, Univerzitet $\mathrm{u}$ Zagrebu, Zagreb.

[4] Z. Ma, F. Zhang, L. Yan, J. Cheng, Fuzzy Knowledge Management for the Semantic Web, XI, 275 p. 67, SpringerVerlag Berlin Heidelberg, 2014.

[5] M. Hans, (2005), Applied fuzzy aritmetican intraduction with engineering applications, Springer.

[6] A. L. Zadeh, (1973) The concept of a lingustic variable and its application to aproximate reasoning, American Elsevire Publishing Company.

[7] E. H. Mamdani, Application of fuzzy logic to approximative reasoning using linguistic systems, IEEE Transc Computer, 26 (1987) pp. 1189-1191.

[8] F. Bouslama, A. Ichikawa, Fuzzy control rules and their natural control laws. Fuzzy sets and systems, 48, 1992, 65-86.

[9] M. Braee, D. A. Rutherford, Theoretical and Linguistic Aspects of the Fuzzy Logic Controller, Automatica, Vol. 15. 1979, pp. 553-577.

[10] P. Kotler, V. Wong, J. Saunders, G. Amstrong, Osnovi marketinga, Zagreb, 2006.

[11] B. Grbac, Načela marketinga, Ekonomski fakultet, Rijeka, 2007.

[12] K. L. Keller, Strategic Brand Menagement, Building-Measuring and Managing Brand Equity, Pearson Education Limited, 2013.

[13] R. T. Rust, A. J. Zahornik, T. I. Keinigham, Returnon quality (ROQ): Making service quality financially accountable measurement, Journal of Marceting, April 1995.

[14] T. Vranešević, Upravljanje markama, Zagreb, Accent, 2007.

[15] S. F. Slater, E. M. Olson, V. K. Reddy, Strategy-Based Performance Measurement, Business Horizons, July-August, 1997, pp. 37-43.

[16] B. D. Krstić, Satisfakcija potrošača: od kvalitativnog ka kvantitativnom mjerenju, Zbornik radova "Razvoj marketinganove tendencije", Ekonomski fakultet u Nišu, Novembar 2001, str. 187-198.

[17] T. Vranešević, M. Marušić, Mjerenje vrijednosti marke, Zbornik Ekonomskog fakulteta u Zagrebu, No1, 2003, pp. 129-148.

[18] A. D. Aaker, Building strong brands, New York, The Free Press, 1996.

[19] M. V. Serdar, M. (1977), Udžbenik statistike, Školska knjiga, Zagreb.

[20] N. S. Sivanandam, S. Sumathi, N. S. Deepa, (2007) Introducion to Fuzzy Logic using MATLAB, Springer/ Verlag Berlin Heidelberg. 